\title{
Potential surgical targets for deep brain stimulation in treatment-resistant depression
}

\author{
Jason S. Hauptman, M.D., ${ }^{1}$ Antonio A. F. DeSalles, M.D., Ph.D., ${ }^{1}$ Randall Espinoza, \\ M.D., M.P.H., ${ }^{2}$ MARK SEDRAK, M.D., ${ }^{1}$ AND WARREN ISHIDA, M.D. ${ }^{1}$
}

Departments of ${ }^{\prime}$ Neurosurgery and ${ }^{2}$ Psychiatry and Biobehavioral Sciences, Geffen School of Medicine at University of California at Los Angeles, California

\begin{abstract}
Object. The goal of this study was to evaluate the definition of treatment-resistant depression (TRD), review the literature regarding deep brain stimulation (DBS) for TRD, and identify potential anatomical and functional targets for future widespread clinical application.

Methods. A comprehensive literature review was performed to determine the current status of DBS for TRD, with an emphasis on the scientific support for various implantation sites.

Results. The definition of TRD is presented, as is its management scheme. The rationale behind using DBS for depression is reviewed. Five potential targets have been identified in the literature: ventral striatum/nucleus accumbens, subgenual cingulate cortex (area 25), inferior thalamic peduncle, rostral cingulate cortex (area 24a), and lateral habenula. Deep brain stimulation electrodes thus far have been implanted and activated in only the first 3 of these structures in humans. These targets have proven to be safe and effective, albeit in a small number of cases.

Conclusions. Surgical intervention for TRD in the form of DBS is emerging as a viable treatment alternative to existing modalities. Although the studies reported thus far have small sample sizes, the results appear to be promising. Various surgical targets, such as the subgenual cingulate cortex, inferior thalamic peduncle, and nucleus accumbens, have been shown to be safe and to lead to beneficial effects with various stimulation parameters. Further studies with larger patient groups are required to adequately assess the safety and efficacy of these targets, as well as the optimal stimulation parameters and long-term effects. (DOI: 10.3171/FOC/2008/25/7/E3)
\end{abstract}

\section{KEY WORDS • deep brain stimulation • depression • psychosurgery}

$\mathrm{M}$ AJOR depressive disorder is a significant health problem affecting $\sim 18$ million people in the US alone, with a $17.1 \%$ lifetime risk of the disease..$^{28}$ The disorder is the most disabling condition for females; two-thirds of all depressed patients are female. Overall, it is the second most disabling condition in more technologically advanced countries and the fourth most disabling condition worldwide. ${ }^{28,35}$ Furthermore, MDD is associated with increases in both medical and psychiatric morbidity and mortality rates (consider, for example, pain, myocardial infarction, or suicide). ${ }^{4,17,22,56,73}$ For this reason, depression carries a significant cost to healthcare delivery and utilization. For patients, the disease can significantly affect quality of life and workplace productivity.

Abbreviations used in this paper: $\mathrm{AC}-\mathrm{PC}=$ anterior commissureposterior commissure; $\mathrm{DBS}=$ deep brain stimulation; $\mathrm{DRN}=$ dorsal raphe nucleus; ECT = electroconvulsive therapy; ITP = inferior thalamic peduncle; $\mathrm{MDD}=$ major depressive disorder; NAC = nucleus accumbens; TMS = transcranial magnetic stimulation; TRD = treatment-resistant depression; VNS = vagus nerve stimulation.
Major depressive disorder is primarily characterized by anhedonia or sadness of mood. It usually disrupts the patient's life at both home and work and is characterized by several concomitant psychological and neurovegetative symptoms such as suicidal ideation, impaired attention and concentration, sleep disturbances, changes in appetite and sexual desire, and psychomotor agitation, or retardation. ${ }^{2}$ It is critical to note that MDD has the potential to be both chronic and recurrent. Approximately $25-40 \%$ of patients experience a recurrence after the index episode, and $60 \%$ experience a recurrence within 5 years. Thirty percent of patients with just 1 episode of depression experience chronic depression, defined as continuous depression for $>1$ year. ${ }^{27,46,65}$ Although more than half of all depressed patients respond to any 1 antidepressant, only two-thirds of this group experience complete remission. Among the remaining patients are those who experience only a partial response and continue to have residual symptoms, do not respond at all, or do not tolerate pharmacotherapy. Factors predictive of resistance to pharmacotherapy include a family history of depression, Axis I comorbidities (for exam- 
J. S. Hauptman et al.

\begin{tabular}{|lc|}
\hline Stage & Treatment Response \\
\hline 0 & No single adequate trial of medication \\
\hline 1 & Failure to respond to an adequate trial of 1 medication \\
2 & $\begin{array}{c}\text { Failure to respond to } 2 \text { different monotherapy trials of } \\
\text { medications with different pharmacologic profiles } \\
\text { Stage 2 plus failure to respond to augmentation } \\
\text { of } 1 \text { of the monotherapies }\end{array}$ \\
\hline 3 & Stage 3 plus failure of a second augmentation strategy \\
4 & Stage 4 plus failure to respond to ECT \\
\hline
\end{tabular}

FIG. 1. Table showing the Thase and Rush classification scheme of TRD.

ple, substance abuse, anxiety disorders, or cognitive disorders), medical comorbidities, extremes in age at onset, the delay from diagnosis to treatment, chronicity of depressive episode, and Axis II comorbidities (personality disorders). ${ }^{15,27,46,55,65}$

Treatment-resistant depression is defined as "the lack of a clinical response after adequate pharmacotherapy has been attempted." 15,55 The practical application of this definition has led to disagreement among psychiatrists, specifically with regard to definitions of adequate duration and magnitude of response and adequacy of treatments. ${ }^{21,36}$ Furthermore, pseudoresistance - due to misdiagnosis of the primary disorder, inadequate dosing, early discontinuation of medication, poor medication adherence, or atypical pharmacokinetics-may result in apparent treatment failure. ${ }^{51}$ One classification scheme, developed by Thase and Rush and utilized by clinicians, identifies criteria with which to judge resistance to therapy (Fig. 1)..$^{52,62,65}$

Therapy for TRD is centered around several principles: 1) ensuring proper diagnosis and treatment, 2) ensuring that any pharmacological trial is of adequate dosage and duration (and that the patient is adhering to the therapy), 3) maximizing medical therapy in cases of a partial response (increasing dosage and/or duration), and 4) optimizing the side effect/symptom profile for medical treatment to improve drug tolerance. ${ }^{27,44,46,51} \mathrm{In}$ addition to medication (including augmentation/adjunctive drugs), combination therapy including psychotherapy has been shown to be beneficial. ${ }^{41}$ When these treatment modalities fail, somatic therapies can be used. ${ }^{12,18}$

Somatic therapy for depression includes several modalities: 1) ECT, 2) VNS, 3) TMS, 4) ablation of deep brain targets, and 5) DBS. Electroconvulsive therapy has a long history of use in TRD and has been shown to have a 50-60\% rate of efficacy. Disadvantages to ECT include acute rapid relapse, greater acute efficacy compared with long-term relief, acute and chronic cognitive side effects (memory disturbance), and lack of appeal to patients. ${ }^{18,50}$ Vagus nerve stimulation has no acute efficacy in the treatment of TRD but may have a role in the treatment of chronic depression. ${ }^{9,54}$ Concerns regarding VNS include its high cost, lack of Medicare or commercial coverage, and inadequacy in treating acute depression. Transcranial magnetic stimulation, which has not been approved by the Food and Drug Administration for the treatment of depression, has demonstrated only modest results. ${ }^{47}$ Stereotactic limbic leukotomy, anterior cingulotomy, anterior capsulotomy, and subcaudate tractotomy have been used in the treatment of intractable neuropsychiatric disease. A 2002 review of stereotactic limbic leukotomy revealed that the procedure has the potential of improving symptoms in 36-50\% of patients with intractable affective and obsessive-compulsive disorders, although side effects such as apathy, urinary incontinence, and memory impairment were reported. ${ }^{43}$ Stereotactic subcaudate tractotomy has also been successful, with a reduction in the suicide rate and improvement in global functioning among patients with uncontrollable affective disorders. ${ }^{6,20,29}$ Approximately 38-61\% of patients with TRD who undergo stereotactic anterior cingulotomy or anterior capsulotomy have shown clinical improvement. ${ }^{11,29,63,64}$ The main disadvantage to ablative therapies is their irreversibility; however, DBS has the advantage of being both reversible and modulatory. Deep brain stimulation has shown promise in the treatment of TRD in some small series and case reports. ${ }^{23,24,32,40,59,64,67,69}$ As an established treatment for pain and movement disorders, the procedure may be more acceptable to patients who are considering a somatic treatment modality. Early reports show good results in the acute phases of therapy, which is an advantage over VNS. In this paper, initial data regarding DBS for the treatment of TRD will be reviewed, with an emphasis on the different putative surgical targets.

\section{Deep Brain Stimulation for MDD}

Ablative and irreversible procedures, such as stereotactic limbic leukotomy, anterior capsulotomy, and anterior cingulotomy, have been successfully performed for intractable neuropsychiatric illness, with acceptable results. . $025,43,48,64^{2}$ Deep brain stimulation, on the other hand, has the distinct advantage of being reversible, nonablative, and modulatory. It may also be more palatable to patients, who see it as an established treatment for parkinsonism, tremors, and dystonia. ${ }^{10}$ Although there have been early reports of successful DBS for MDD, 23,24,32,40,59,64,67,69 critical questions remain. The most appropriate target, optimal stimulation parameters, and long-term effects and efficacy remain uncertain. In response to a published article describing DBS for psychiatric disease, Dr. Cosgrove poignantly wrote that "deep brain stimulation may provide a unique opportunity to help patients who suffer horribly from the consequences of severe depression.... early efforts must go forward only with the highest ethical, moral, and scientific standards to ensure that this historic opportunity is not wasted.... much is at stake." ${ }^{\prime 10}$ This notion is essential. 


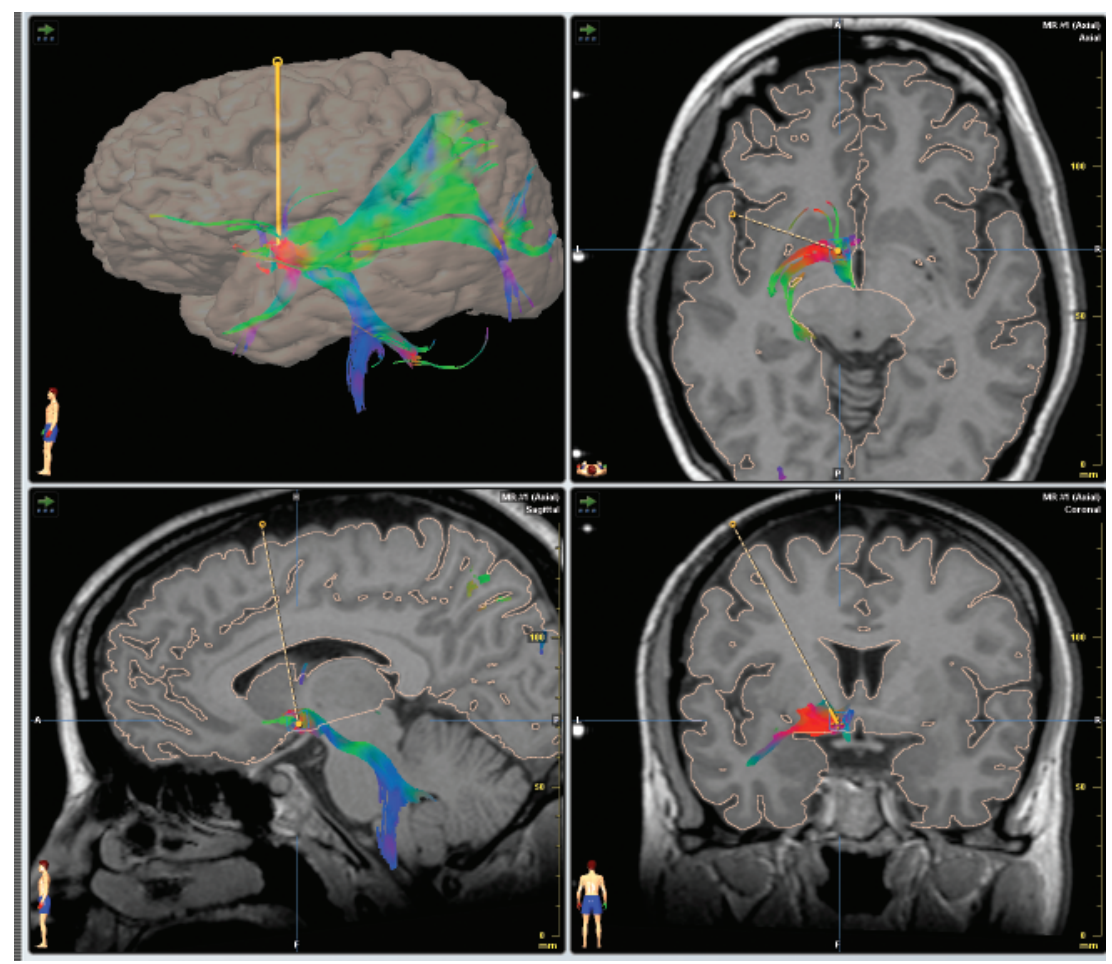

FIG. 2. Diffusion tensor and stereotactic images showing localization of the ventral striatum/NAC. Note the projections to and from the ventral tegmentum, brainstem, orbitofrontal cortex, insula, cingulate cortex, and mesolimbic structures. Fractional anisotropy $=0.2$; minimum fiber length $36 \mathrm{~mm}$.

\section{Nucleus Accumbens and Ventral Striatum}

The reward circuitry of the ventral striatum and NAC has been associated with drug addiction and depression for many years (Fig. 2). ${ }^{30,42,45,66}$ Changes in dopaminergic receptor densities in this region have been associated with inescapable stress and learned helplessness. ${ }^{33}$ In mouse models, genetic predisposition may inhibit the metabolism and release of dopamine in the NAC under stressful conditions, providing a susceptibility to learned helplessness and thus depression..$^{70}$ In models of hypercortisolism-induced depression, high levels of cortisol have been associated with dopamine attenuation in the NAC. ${ }^{49}$ Furthermore, empirical data obtained during TMS have suggested that increased mesolimbic dopamine within the NAC (as well as other structures) may contribute to successful neuromodulation for depression. ${ }^{26,72}$ The NAC is also involved in processing affective stimuli and has a potential role in depression, according to functional MR imaging studies. ${ }^{42}$

From a neuroanatomical perspective, the NAC and ventral striatum receive projections mainly from the anterior cingulate cortex, agranular insular cortex, and orbitofrontal cortex. Whereas the core of the NAC receives input from all of these areas, the shell receives input mainly from the subgenual and pregenual cingulate cortices. ${ }^{31}$ The NAC and ventral striatum then project to the dorsomedial nucleus of the thalamus by way of the ventral tegmental area, ventral pallidum, and substantia nigra-which in turn projects back to the prefrontal cortex, orbitofrontal cortex, anterior cingulate cortex, amygdala, and hypothalamus; this forms the limbic loop of the basal ganglia. ${ }^{31,59}$ The association of the NAC with areas intimately involved in depression makes it a practical candidate for neuromodulation.

In 2004 Aouizerate et al. ${ }^{1}$ reported their first case of DBS in the ventral caudate in a patient suffering from intractable obsessive-compulsive disorder and concomitant major depression (the depression did respond to medical therapy). The patient underwent bilateral electrode implantation so that the deepest contacts were located in the NAC, and the superficial contacts in the ventromedial caudate. The tip of the right electrode was located $3 \mathrm{~mm}$ below the AC-PC line, $36.5 \mathrm{~mm}$ anterior to the $\mathrm{PC}$, and $8.9 \mathrm{~mm}$ lateral to the AC-PC line; the left electrode was located $31.4 \mathrm{~mm}$ anterior to the PC line and $7.6 \mathrm{~mm}$ lateral and $1.7 \mathrm{~mm}$ below the AC-PC line. Stimulation of the bilateral NAC and ventral caudate at $130 \mathrm{~Hz}$ resulted in significant relief from depression and anxiety, until a remission at 6 months. Global function improved and neuropsychological scores were unaffected. Unfortunately, the psychiatric comorbidity in this patient and medication-responsive nature of the depression limit extrapolation of these data to patients with TRD only.

In a recently published report, Schlaepfer et al. ${ }^{59}$ have described bilateral implantation in the shell and core of the NAC in 3 patients with TRD. The coordinates used were as follows: $1.5 \mathrm{~mm}$ rostral to the AC and $4 \mathrm{~mm}$ ventral and 7$8 \mathrm{~mm}$ lateral to the midline of the third ventricle. When all of the patients received continuous stimulation at $145 \mathrm{~Hz}$, they showed continual improvement in scores for anhedonia and depression (without any negative side effects) and worse scores when the stimulator was turned off. Furthermore, PET studies performed before and during 

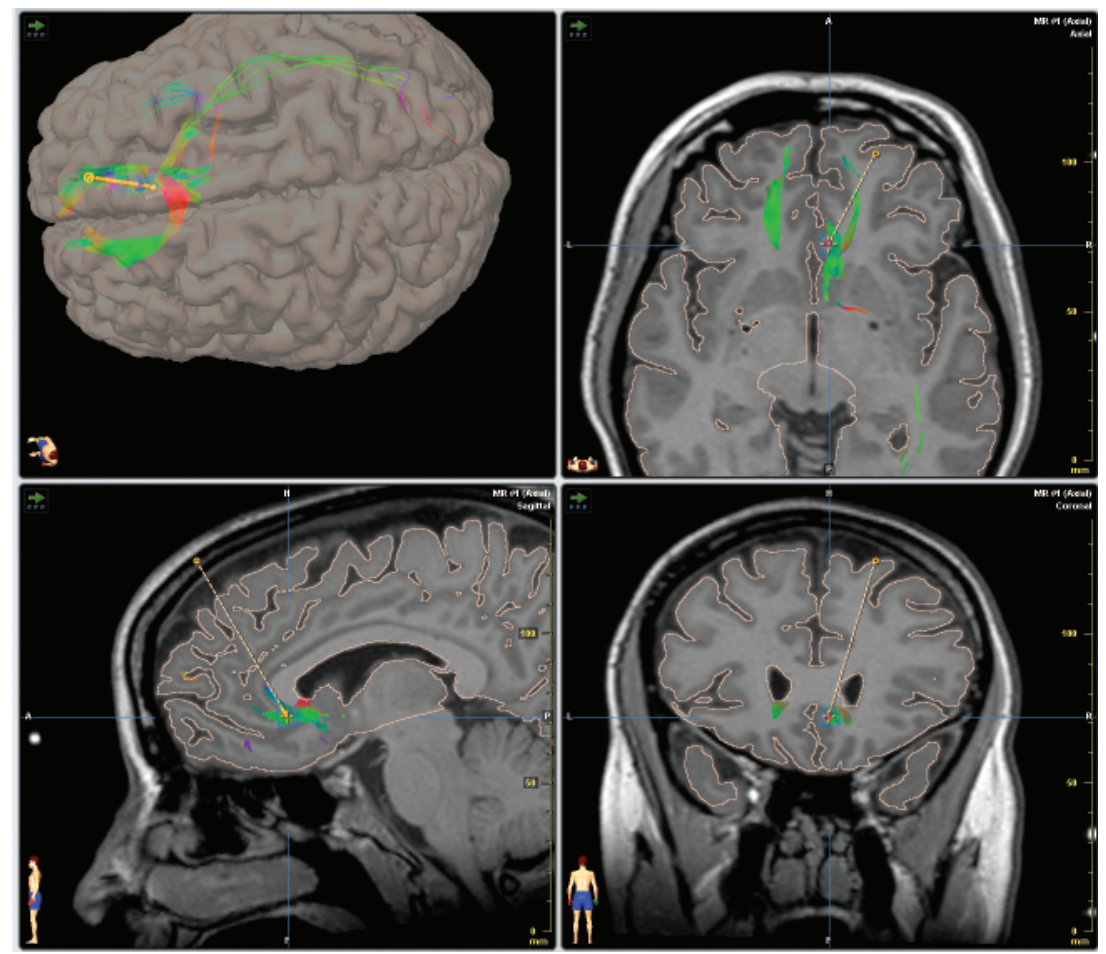

FIG. 3. Diffusion tensor and stereotactic images demonstrating localization of the subgenual cingulate cortex. Note the projections to and from the striatum, dorsal frontal cortices, and orbitofrontal cortices. Fractional anisotropy $=0.2$; minimum fiber length $36 \mathrm{~mm}$.

stimulation demonstrated a significant increase in the metabolism of the bilateral ventral striatum, bilateral dorsolateral and dorsomedial prefrontal cortices, cingulate cortex, and bilateral amygdala after 1 week of therapy. Metabolism of the ventral and ventrolateral medial prefrontal cortex, shown in previous studies to be hyperactive in depression, was decreased. ${ }^{7}$ Complete remission of depression was not achieved, but the clinical follow-up was 23 weeks in 1 patient and 5-7 weeks in the other 2. Regardless, neuromodulation of the ventral caudate and/or NAC appears to be safe and efficacious.

\section{Subgenual Cingulate Cortex: Area 25}

The subgenual cingulate cortex, as discussed in the previous section, has critical projections to and from the ventral striatum, NAC shell, and limbic cortical loop (Fig. 3). The orbitofrontal, dorsomedial prefrontal, dorsolateral prefrontal, and dorsal cingulate cortices have reciprocal connections to the subgenual cingulate cortex according to tracer studies. This area also has reciprocal connections with the centromedial amygdala, bed nucleus of the stria terminalis, hypothalamus, and serotonergic regions of the DRNs and periaqueductal gray; these reciprocal connections support the notion that the subgenual cingulate is involved in visceromotor and vegetative physiology. ${ }^{31}$ These connections have been confirmed using diffusion tractography in humans. ${ }^{24,60}$

Early work by Mayberg et al. ${ }^{39}$ has demonstrated the integral role played by the subgenual cingulate cortex in both normal and pathological shifts in mood. Increases in limbic and paralimbic blood flow (as measured using PET) occur in the subgenual cingulate cortex and anterior insula during sadness; there is a significant inverse correlation between blood flow in the subgenual cingulate cortex and right dorsolateral prefrontal cortex. ${ }^{34,39}$ This inverse correlation has been confirmed by quantitative cytochrome oxidase histochemistry in rodent models. ${ }^{61}$ A clinical response to antidepressants is associated with limbic and striatal (subgenual cingulate cortex, hippocampus, insula, and pallidum) decreases in metabolism and dorsal cortical (prefrontal, parietal, anterior, and posterior cingulate cortex) increases in metabolism. ${ }^{13,38}$ Furthermore, abnormalities in the subgenual cingulate volume and cytoarchitecture have also been noted in patients with familial affective disorders. ${ }^{5,19}$ Highfrequency repetitive TMS of the dorsolateral prefrontal cortex has been correlated with SPECT-demonstrated changes in the ipsilateral subgenual cingulate cortex and striatum, further underscoring their anatomical and metabolic connectivity. These data suggest that functional inhibition of the subgenual cingulate cortex by using DBS mimics or enhances the metabolic effects of antidepressant therapy.

In 2005 Mayberg et al. ${ }^{40}$ implanted DBS electrodes in the bilateral subgenual cingulate cortex in 6 patients with TRD. Blinded, sequential intraoperative stimulation at $130 \mathrm{~Hz}$ was applied to discover the thresholds for safe and effective stimulation. When stimulation was on, patients reported positive emotional phenomena, with psychomotor slowing and lightheadedness occurring on stimulation above the 7$\mathrm{V}$ threshold. In the acute postoperative period patients experienced reproducible increases in activity and mood scores, changes that failed to occur during sham stimula- 

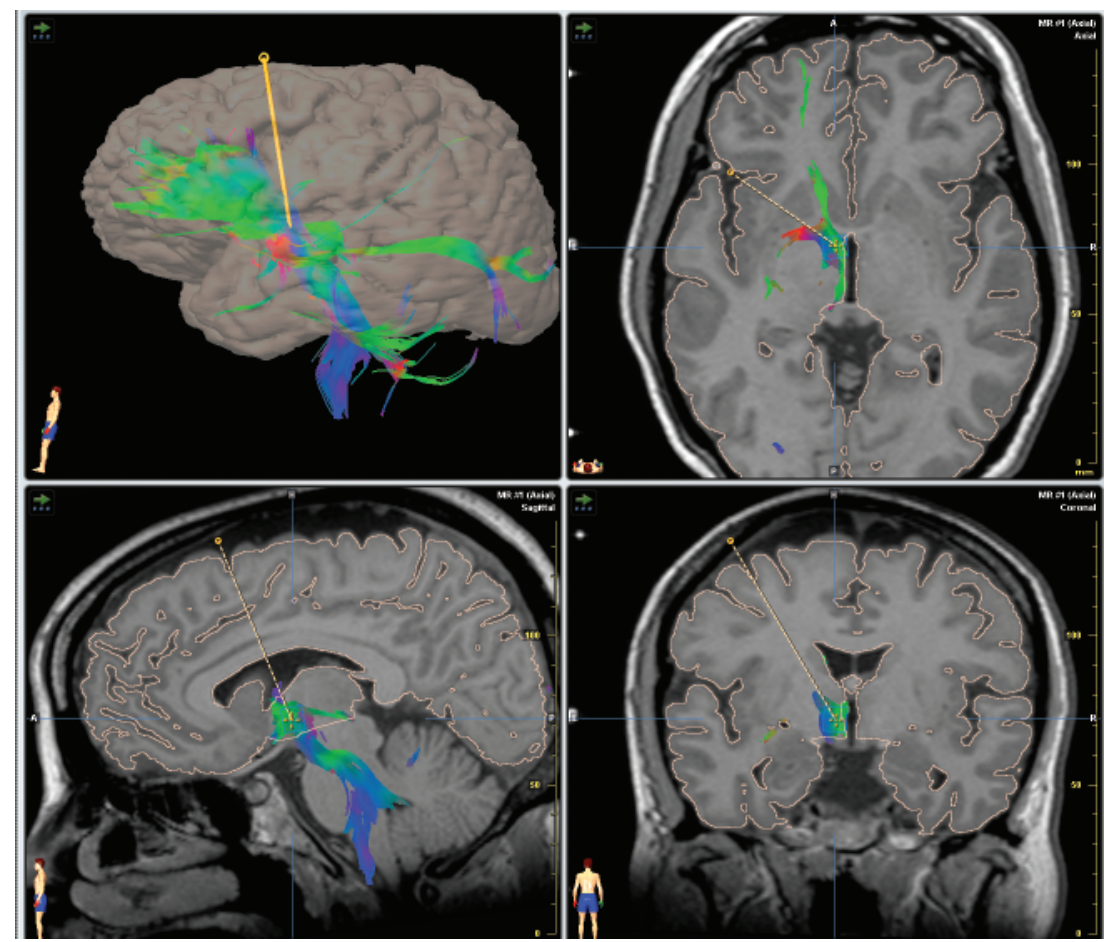

FIG. 4. Diffusion tensor and stereotactic images revealing localization of the ITP. Note the projections throughout the frontal lobe, ventral tegmentum/brainstem, and mesolimbic structures. Fractional anisotropy $=0.2$, minimum fiber length $36 \mathrm{~mm}$.

tion. Chronic stimulation at $130 \mathrm{~Hz}$ resulted in a significant response and remission of depression in 4 of the 6 patients at 6 months; in the 2 remaining patients, 1 experienced a significant reduction in depression over the first 4 months that fluctuated over time and remained submaximal, and the other patient had no response. Furthermore, the stimulation benefit seemed to continue for 3-4 weeks after stimulation was ended until depression recurred. Positron emission tomography studies performed in the responders corresponded to the antidepressant effects noted earlier by Mayberg et al. ${ }^{38}$ - that is, a decrease in limbic and striatal cerebral blood flow and an increase in dorsal cortical regions. Postoperative neuropsychological testing showed improvement in many preoperatively deficient areas and no impairment in orbitofrontal functioning. In this small series, the subgenual cingulate cortex was a stimulation target with potentially high efficacy and low risks, although further work is necessary to identify anatomical or physiological risk factors for unresponsiveness to therapy.

\section{Inferior Thalamic Peduncle}

The ITP has been identified by Velasco et al ${ }^{68}$ as a potential stimulation target for refractory depression (Fig. 4). The ITP is a bundle of fibers that connects the nonspecific thalamic system to the orbitofrontal cortex; this system induces electrocortical synchronization and aids the inhibition of input of irrelevant stimuli (thus providing selective attention). ${ }^{23,68}$ According to functional imaging and PET, both the ITP and orbitofrontal cortex have proven to be hyperactive in depression, a phenomenon that reverses with effective pharmacological treatment. ${ }^{68}$ When these areas are lesioned, hyperkinesias and increased attentiveness result. ${ }^{68}$ Thus, neuromodulation with high-frequency DBS may be effective during depression episodes.

In 2005 Jiménez et al. ${ }^{23}$ published their first report of successful DBS electrode implantation in the ITP for refractory depression. In that case a 49-year-old woman with severe TRD and multiple hospitalizations received bilateral tetrapolar electrodes in the ITP, which were continuously stimulated at $130 \mathrm{~Hz}$. Both EEG studies and clinical changes following a period of acute stimulation with temporary electrodes guided permanent electrode placement. Optimal electrode placement was determined to be $5.0 \mathrm{~mm}$ lateral to the midline, $4.0 \mathrm{~mm}$ behind the $\mathrm{AC}$, and $0.5 \mathrm{~mm}$ below the AC-PC line. Postoperatively, while stimulation was on, the patient experienced global improvement in function, neuropsychological scores, and Hamilton depression scores; this effect was reversed when the stimulator was off. Interestingly, there was an initial temporary antidepressant effect after electrode placement even without stimulation, an occurrence similar to that in some patients who experience transient tremor relief after the placement of thalamic electrodes. Overall, the therapeutic effect of stimulation was believed to be attributable to the inhibition of the orbitofrontal cortex, which is typically overactive in depressed patients. ${ }^{23}$ Although this initial report indicates promise, large-scale trials of implantation are necessary to determine the efficacy and safety of this target.

\section{Rostral Cingulate Cortex: Area 24a}

Drs. Sakas and Panourias ${ }^{57}$ proposed the rostral cingulate gyrus (Brodmann area 24a) as an appropriate therapeutic 


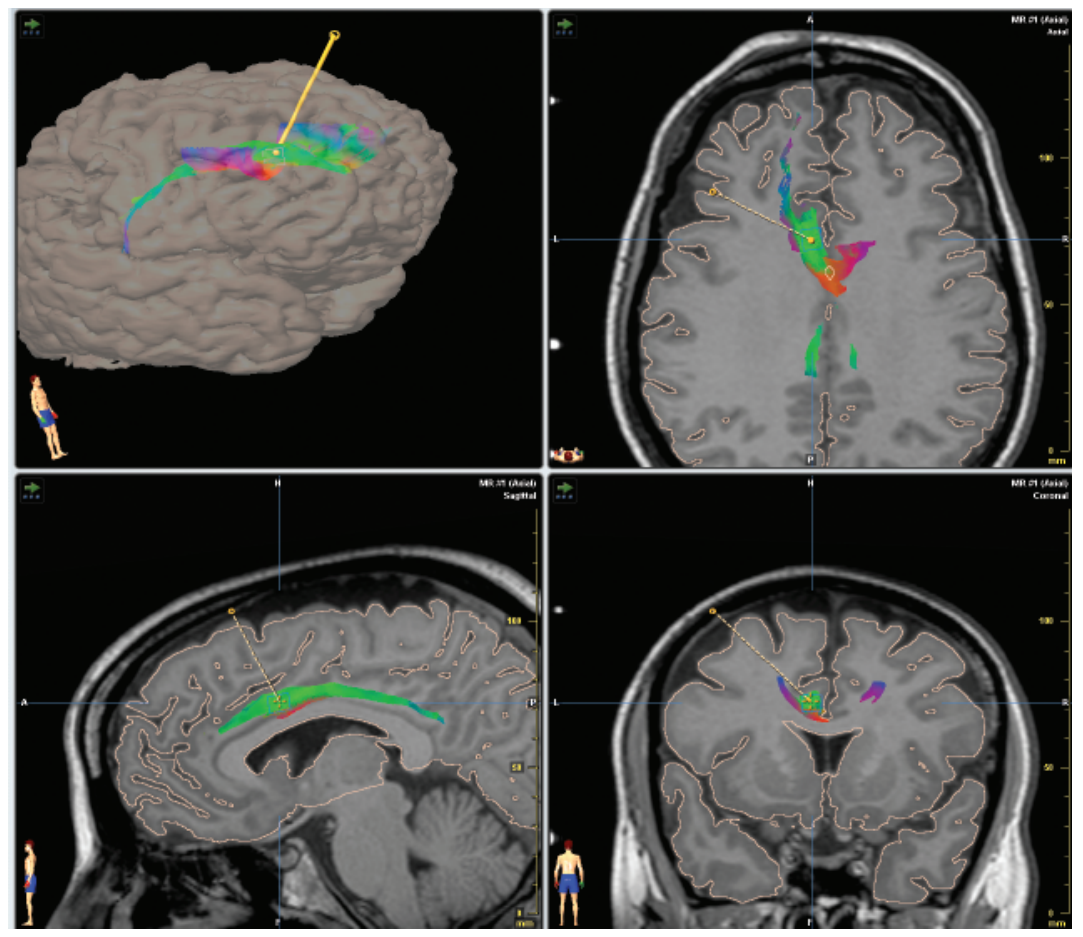

FIG. 5. Diffusion tensor and stereotactic images showing localization of the rostral cingulate. Note the projections to and from the cingulate cortex, dorsal frontal cortices, and across corpus callosum. Fractional anisotropy $=0.2 ;$ minimum fiber length $36 \mathrm{~mm}$.

target for TRD (Fig. 5). The rostral cingulate cortex is thought to mediate between the dorsal (dorsolateral prefrontal cortex, dorsal anterior cingulate cortex, inferior parietal cortex, and striatum) and ventral (paralimbic cortex, subcortical hypothalamus, insula, subgenual cingulate cortex, and brainstem) areas of limbic-cortical dysregulation in depression. ${ }^{37,57}$ Smaller volumes of the rostral cingulate cortex have been found in boys with subclinical depression. ${ }^{3}$

Metabolic studies have confirmed that the rostral cingulate cortex shows increased glucose utilization in patients who respond to antidepressants (as opposed to nonresponders), with metabolic activity predicting the magnitude of the response to pharmacotherapy. ${ }^{37,53,57}$ Rostral cingulate cortex involvement in depression has also been corroborated by functional MR imaging data. ${ }^{14}$ This area's central role in mediating the dysfunction between the ventral (neurocognitive) and dorsal (somatic) compartments makes it an attractive candidate for neuromodulation. No electrode has yet been implanted in the rostral cingulate cortex in humans; however, stereotactic lesioning of this area has shown beneficial effects. ${ }^{64}$

\section{Lateral Habenula}

The lateral habenula has been proposed as a putative target for DBS; however, no human trials appear in the literature (Fig. 6) ${ }^{58}$ Depression is associated with an increase in the activation of the lateral habenular nucleus, downregulation of monoaminergic (norepinephrine, serotonin, and dopamine) systems, and stimulation of the hypothalamicpituitary axis.$^{58}$ From an anatomical standpoint, the habe- nular nuclear complex projects to the DRNs and locus ceruleus (both with projections to the medial prefrontal cortex). ${ }^{16,58}$ In depressed rats, metabolic activity and regional cerebral blood flow in the lateral habenula are increased. 8,58 Global metabolic rates are decreased in the forebrain, and regional metabolic rates are decreased in the dorsal medial prefrontal cortex and anterior ventral nucleus of the thalamus. The administration of monoamine oxidase inhibitor antidepressants prevents the hypermetabolism found in the lateral habenula. ${ }^{8,58}$

Habenular lesions attenuate the rise of serotonin in the DRNs under stressful conditions (leading to decreased serotonin in the DRNs projection areas via negative feedback), a process that could otherwise lead to depression. ${ }^{58}$ When the lateral habenula is inhibited by electrical stimulation in rats, norepinephrine in the hippocampus/prefrontal cortex increases, as does serotonin in the striatal circuits (independent of DRNs control). ${ }^{16,58}$ High-frequency stimulation attenuates the rise of serotonin in the DRNs, which would lead to higher serotonin levels in projection areas. ${ }^{16,58}$ In a study by Yang et al. ${ }^{71}$ depressed rats were lesioned in the lateral habenula, which resulted in decreased behavioral measures of depression (less immobility time during forced swimming) as well as lower levels of serotonin in the DRN by microdialysis. Thus, functional inhibition of this area using high-frequency DBS may have therapeutic benefit.

\section{Conclusions}

Neuromodulation of the limbic circuit shows great potential for restoring functionality to patients crippled by TRD. Although the ventral striatum/NAC, subgenual cin- 


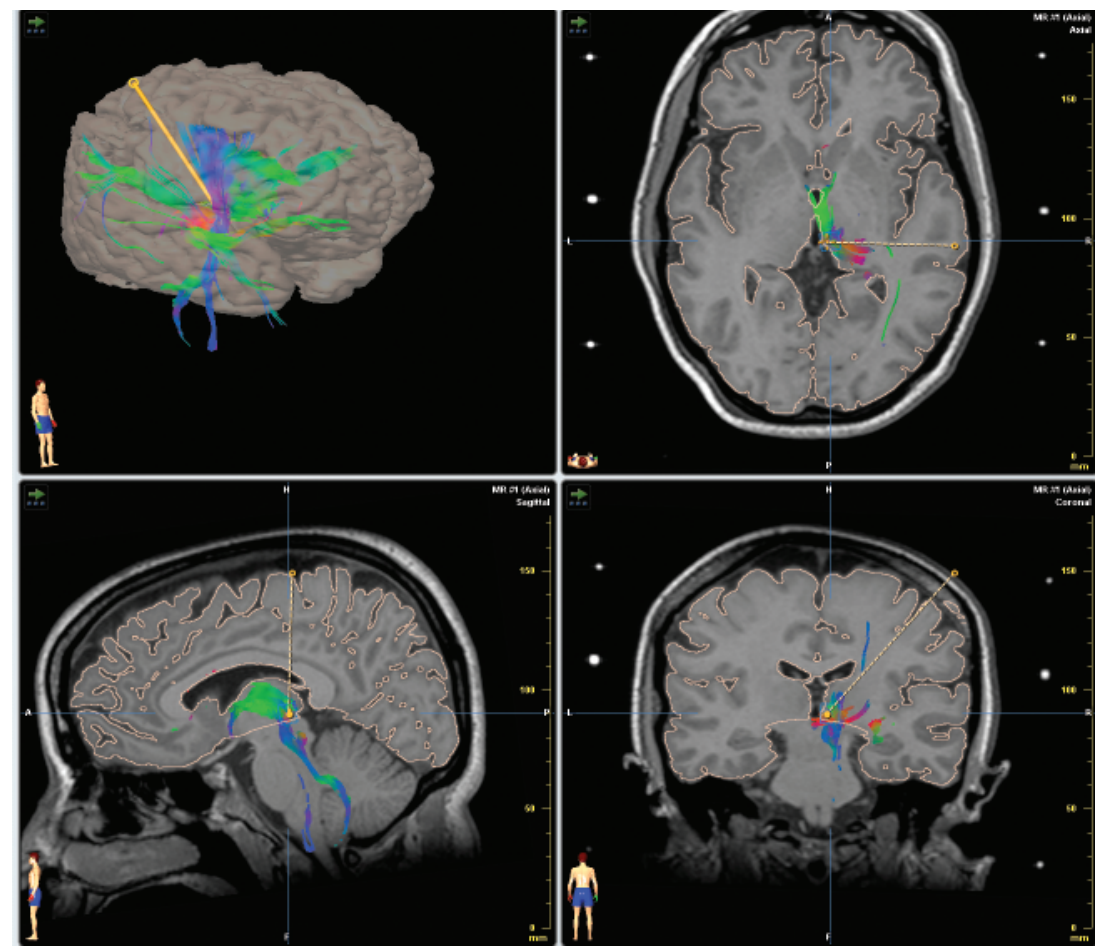

FIG. 6. Diffusion tensor and stereotactic images demonstrating localization of the lateral habenula. Note the projections to and from the dorsal frontal cortices, orbitofrontal cortex, insula and mesolimbic areas, and ventral tegmentum/brainstem. Fractional anisotropy $=0.2$; minimum fiber length $36 \mathrm{~mm}$.

gulate cortex, ITP, rostral cingulate cortex, and lateral habenula are all reasonable targets for DBS electrode implantation, the stimulation of any of these locations is likely to modify the same or similar circuits, as the different areas appear to be anatomically and functionally related. Whereas early case reports and series have provided promising data regarding functional outcome, it is clear that a largescale trial must be conducted to adequately assess the safety and efficacy of stimulation for depression. Data from such studies will provide information regarding optimal target localization, stimulation parameters, and adverse effects.

This is a critical and exciting time for the functional neurosurgeon. Modern neuromodulation now offers hope to many people who may regain the capacity for normal social interaction and eventually return to work. Beyond the negative history of psychosurgery, we have the opportunity to advance and broaden the spectrum of DBS applications. A solid scientific rationale, a flawless experimental protocol, and an adherence to a strong code of ethics are vital to ensuring the success of these endeavors.

\section{References}

1. Aouizerate B, Cuny E, Martin-Guehl C, Guehl D, Amieva H, Benazzouz A, et al: Deep brain stimulation of the ventral caudate nucleus in the treatment of obsessive-compulsive disorder and major depression. Case report. J Neurosurg 101:682-686, 2004

2. Belmaker RH, Agam G: Major depressive disorder. N Engl J Med 358:55-68, 2008

3. Boes AD, McCormick LM, Coryell WH, Nopoulos P: Rostral anterior cingulate cortex volume correlates with depressed mood in normal healthy children. Biol Psychiatry 63: 391-397, 2008

4. Bogner HR, Morales KH, Post EP, Bruce ML: Diabetes, depression, and death: a randomized controlled trial of a depression treatment program for older adults based in primary care (PROSPECT). Diabetes Care 30:3005-3010, 2007

5. Bouras C, Kövari E, Hof PR, Riederer BM, Giannakopoulos P: Anterior cingulate cortex pathology in schizophrenia and bipolar disorder. Acta Neuropathol 102:373-379, 2001

6. Bridges PK, Bartlett JR, Hale AS, Poynton AM, Malizia AL, Hodgkiss AD: Psychosurgery: stereotactic subcaudate tractomy. An indispensable treatment. Br J Psychiatry 165:599-613, 1994

7. Brody AL, Barsom MW, Bota RG, Saxena S: Prefrontal-subcortical and limbic circuit mediation of major depressive disorder. Semin Clin Neuropsychiatry 6:102-112, 2001

8. Caldecott-Hazard S, Mazziotta J, Phelps M: Cerebral correlates of depressed behavior in rats, visualized using 14C-2-deoxyglucose autoradiography. J Neurosci 8:1951-1961, 1988

9. Corcoran CD, Thomas P, Phillips J, O'Keane V: Vagus nerve stimulation in chronic treatment-resistant depression: preliminary findings of an open-label study. Br J Psychiatry 189:282-283, 2006

10. Cosgrove GR: Deep brain stimulation and psychosurgery. J Neurosurg 101:574-576, 2004

11. Cosgrove GR, Rauch SL: Stereotactic cingulotomy. Neurosurg Clin N Am 14:225-235, 2003

12. Dougherty DD, Rauch SL: Somatic therapies for treatment-resistant depression: new neurotherapeutic interventions. Psychiatr Clin North Am 30:31-37, 2007

13. Drevets WC, Bogers W, Raichle ME: Functional anatomical correlates of antidepressant drug treatment assessed using PET measures of regional glucose metabolism. Eur Neuropsychopharmacol 12:527-544, 2002 
14. Ebmeier K, Rose E, Steele D: Cognitive impairment and fMRI in major depression. Neurotox Res 10:87-92, 2006

15. Fava M: Diagnosis and definition of treatment-resistant depression. Biol Psychiatry 53:649-659, 2003

16. Ferraro G, Montalbano ME, Sardo P, La Grutta V: Lateral habenular influence on dorsal raphe neurons. Brain Res Bull 41:4752,1996

17. Frasure-Smith N, Lespérance F, Talajic M: Depression following myocardial infarction. Impact on 6-month survival. JAMA 270: 1819-1825, 1993

18. George MS, Nahas Z, Borckardt JJ, Anderson B, Foust MJ, Burns $\mathrm{C}$, et al: Brain stimulation for the treatment of psychiatric disorders. Curr Opin Psychiatry 20:250-259, 2007

19. Hirayasu Y, Shenton ME, Salisbury DF, Kwon JS, Wible CG, Fischer IA, et al: Subgenual cingulate cortex volume in first-episode psychosis. Am J Psychiatry 156:1091-1093, 1999

20. Hodgkiss AD, Malizia AL, Bartlett JR, Bridges PK: Outcome after the psychosurgical operation of stereotactic subcaudate tractotomy, 1979-1991. J Neuropsychiatry Clin Neurosci 7:230234, 1995

21. Husain SS, Kevan IM, Linnell R, Scott AI: What do psychiatrists mean by medication resistance as an indication for electroconvulsive therapy? J ECT 21:211-213, 2005

22. Jaffe AS, Krumholz HM, Catellier DJ, Freedland KE, Bittner V, Blumenthal JA, et al: Prediction of medical morbidity and mortality after acute myocardial infarction in patients at increased psychosocial risk in the Enhancing Recovery in Coronary Heart Disease Patients (ENRICHD) study. Am Heart J 152:126-135, 2006

23. Jiménez F, Velasco F, Salin-Pascual R, Hernández JA, Velasco M, Criales JL, et al: A patient with a resistant major depression disorder treated with deep brain stimulation in the inferior thalamic peduncle. Neurosurgery 57:585-593, 2005

24. Johansen-Berg H, Gutman DA, Behrens TE, Matthews PM, Rushworth MF, Katz E, et al: Anatomical connectivity of the subgenual cingulate region targeted with deep brain stimulation for treatment-resistant depression. Cereb Cortex 18:1374-1383, 2007)

25. Jung HH, Kim CH, Chang JH, Park YG, Chung SS, Chang JW: Bilateral anterior cingulotomy for refractory obsessive-compulsive disorder: Long-term follow-up results. Stereotact Funct Neurosurg 84:184-189, 2006

26. Keck ME, Welt T, Müller MB, Erhardt A, Ohl F, Toschi N, et al: Repetitive transcranial magnetic stimulation increases the release of dopamine in the mesolimbic and mesostriatal system. Neuropharmacology 43:101-109, 2002

27. Keller MB: Issues in treatment-resistant depression. J Clin Psychiatry 66 (8 Suppl):5-12, 2005

28. Kessler RC, Chiu WT, Demler O, Merikangas KR, Walters EE: Prevalence, severity, and comorbidity of 12-month DSM-IV disorders in the National Comorbidity Survey Replication. Arch Gen Psychiatry 62:617-627, 2005

29. Kim MC, Lee TK, Choi CR: Review of long-term results of stereotactic psychosurgery. Neurol Med Chir 42 (Tokyo):365-371, 2002

30. Kombian SB, Malenka RC: Simultaneous LTP of non-NMDAand LTD of NMDA-receptor-mediated responses in the nucleus accumbens. Nature 368:242-246, 1994

31. Kopell BH, Greenberg BD: Anatomy and physiology of the basal ganglia: implications for DBS in psychiatry. Neurosci Biobehav Rev 32:408-422, 2008

32. Kosel M, Sturm V, Frick C, Lenartz D, Zeidler G, Brodesser D, et al: Mood improvement after deep brain stimulation of the internal globus pallidus for tardive dyskinesia in a patient suffering from major depression. J Psychiatr Res 41:801-803, 2007

33. Kram ML, Kramer GL, Ronan PJ, Steciuk M, Petty F: Dopamine receptors and learned helplessness in the rat: an autoradiographic study. Prog Neuropsychopharmacol Biol Psychiatry 26:639645, 2002

34. Liotti M, Mayberg HS, Brannan SK, McGinnis S, Jerabek P, Fox
PT: Differential limbic — cortical correlates of sadness and anxiety in healthy subjects: implications for affective disorders. Biol Psychiatry 48:30-42, 2000

35. Lopez AD, Mathers CD, Ezzati M, Jamison DT, Murray CJ: Global and regional burden of disease and risk factors, 2001: systematic analysis of population health data. Lancet 367:17471757,2006

36. Malhi GS, Parker GB, Crawford J, Wilhelm K, Mitchell PB: Treatment-resistant depression: resistant to definition? Acta Psychiatr Scand 112:302-309, 2005

37. Mayberg HS: Limbic-cortical dysregulation: a proposed model of depression. J Neuropsychiatry Clin Neurosci 9:471-481, 1997

38. Mayberg HS, Brannan SK, Tekell JL, Silva JA, Mahurin RK, McGinnis S, et al: Regional metabolic effects of fluoxetine in major depression: serial changes and relationship to clinical response. Biol Psychiatry 48:830-843, 2000

39. Mayberg HS, Liotti M, Brannan SK, McGinnis S, Mahurin RK, Jerabek PA, et al: Reciprocal limbic-cortical function and negative mood: converging PET findings in depression and normal sadness. Am J Psychiatry 156:675-682, 1999

40. Mayberg HS, Lozano AM, Voon V, McNeely HE, Seminowicz D, Hamani C, et al: Deep brain stimulation for treatment-resistant depression. Neuron 45:651-660, 2005

41. McPherson S, Cairns P, Carlyle J, Shapiro DA, Richardson P, Taylor D: The effectiveness of psychological treatments for treatment-resistant depression: a systematic review. Acta Psychiatr Scand 111:331-340, 2005

42. Monk CS, Klein RG, Telzer EH, Schroth EA, Mannuzza S, Moulton JL III, et al: Amygdala and nucleus accumbens activation to emotional facial expressions in children and adolescents at risk for major depression. Am J Psychiatry 165:90-98, 2008

43. Montoya A, Weiss AP, Price BH, Cassem EH, Dougherty DD, Nierenberg AA, et al: Magnetic resonance imaging-guided stereotactic limbic leukotomy for treatment of intractable psychiatric disease. Neurosurgery 50:1043-1052, 2002

44. Nemeroff CB: Prevalence and management of treatment-resistant depression. J Clin Psychiatry 68 (8 Suppl): 17-25, 2007

45. Nie Z, Yuan X, Madamba SG, Siggins GR: Ethanol decreases glutamatergic synaptic transmission in rat nucleus accumbens in vitro: naloxone reversal. J Pharmacol Exp Ther 266:17051712,1993

46. Nierenberg AA, Katz J, Fava M: A critical overview of the pharmacologic management of treatment-resistant depression. Psychiatr Clin North Am 30:13-29, 2007

47. O'Reardon JP, Solvason HB, Janicak PG, Sampson S, Isenberg KE, Nahas Z, et al: Efficacy and safety of transcranial magnetic stimulation in the acute treatment of major depression: a multisite randomized controlled trial. Biol Psychiatry 62:1208-1216, 2007

48. Oliver B, Gascón J, Aparicio A, Ayats E, Rodriguez R, Mastro De León JL, et al: Bilateral anterior capsulotomy for refractory obsessive-compulsive disorders. Stereotact Funct Neurosurg 81:9095, 2003

49. Pacak K, Tjurmina O, Palkovits M, Goldstein DS, Koch CA, Hoff $\mathrm{T}$, et al: Chronic hypercortisolemia inhibits dopamine synthesis and turnover in the nucleus accumbens: an in vivo microdialysis study. Neuroendocrinology 76:148-157, 2002

50. Pagnin D, de Queiroz V, Pini S, Cassano GB: Efficacy of ECT in depression: a meta-analytic review. J ECT 20:13-20, 2004

51. Parker GB, Malhi GS, Crawford JG, Thase ME: Identifying "paradigm failures" contributing to treatment-resistant depression. J Affect Disord 87:185-191, 2005

52. Petersen T, Papakostas GI, Posternak MA, Kant A, Guyker WM, Iosifescu DV, et al: Empirical testing of two models for staging antidepressant treatment resistance. J Clin Psychopharmacol 25:336-341, 2005

53. Pizzagalli D, Pascual-Marqui RD, Nitschke JB, Oakes TR, Larson $\mathrm{CL}$, Abercrombie HC, et al: Anterior cingulate activity as a predictor of degree of treatment response in major depression: evi- 


\section{Deep brain stimulation targets in treatment-resistant depression}

dence from brain electrical tomography analysis. Am J Psychiatry 158:405-415, 2001

54. Rush AJ, Marangell LB, Sackeim HA, George MS, Brannan SK, Davis SM, et al: Vagus nerve stimulation for treatment-resistant depression: a randomized, controlled acute phase trial. Biol Psychiatry 58:347-354, 2005

55. Rush AJ, Thase ME, Dubé S: Research issues in the study of difficult-to-treat depression. Biol Psychiatry 53:743-753, 2003

56. Rutledge T, Reis SE, Olson MB, Owens J, Kelsey SF, Pepine CJ, et al: Depression symptom severity and reported treatment history in the prediction of cardiac risk in women with suspected myocardial ischemia: The NHLBI-sponsored WISE study. Arch Gen Psychiatry 63:874-880, 2006

57. Sakas DE, Panourias IG: Rostral cingulate gyrus: a putative target for deep brain stimulation in treatment-refractory depression. Med Hypotheses 66:491-494, 2006

58. Sartorius A, Henn FA: Deep brain stimulation of the lateral habenula in treatment resistant major depression. Med Hypotheses 69:1305-1308, 2007

59. Schlaepfer TE, Cohen MX, Frick C, Kosel M, Brodesser D, Axmacher N, et al: Deep brain stimulation to reward circuitry alleviates anhedonia in refractory major depression. Neuropsychopharmacology 33:368-377, 2008

60. Sedrak M, Gorgulho A, De Salles A, et al: The role of modern imaging modalities on deep brain stimulation targeting for mental illness. Acta Neurochir Suppl [in press], 2008

61. Shumake J, Poremba A, Edwards E, Gonzalez-Lima F: Congenital helpless rats as a genetic model for cortex metabolism in depression. Neuroreport 11:3793-3798, 2000

62. Souery D, Amsterdam J, de Montigny C, Lecrubier Y, Montgomery S, Lipp O, et al: Treatment resistant depression: methodological overview and operational criteria. Eur Neuropsychopharmacol 9:83-91, 1999

63. Spangler WJ, Cosgrove GR, Ballantine HT Jr, Cassem EH, Rauch SL, Nierenberg A, et al: Magnetic resonance image-guided stereotactic cingulotomy for intractable psychiatric disease. Neurosurgery 38:1071-1078, 1996

64. Steele JD, Christmas D, Eljamel MS, Matthews K: Anterior cingulotomy for major depression: clinical outcome and relationship to lesion characteristics. Biol Psychiatry 63:670-677, 2007

65. Thase ME, Rush AJ: Treatment resistant depression, in Bloom FE,
Kupfer DJ (eds): Psychopharmacology: The Fourth Generation of Progress. New York: Raven Press, 1995, pp 1081-1097

66. Thomas MJ, Malenka RC, Bonci A: Modulation of long-term depression by dopamine in the mesolimbic system. J Neurosci 20:5581-5586, 2000

67. van Kuyck K, Gabriëls L, Cosyns P, Arckens L, Sturm V, Rasmussen S, et al: Behavioural and physiological effects of electrical stimulation in the nucleus accumbens: a review. Acta Neurochir Suppl 97:375-391, 2007

68. Velasco F, Velasco M, Jiménez F, Velasco AL, Salin-Pascual R: Neurobiological background for performing surgical intervention in the inferior thalamic peduncle for treatment of major depression disorders. Neurosurgery 57:439-448, 2005

69. Velasco M, Velasco F, Jiménez F, Carrillo-Riuz JD, Velasco AL, Salín-Pascual R: Electrocortical and behavioral responses elicited by acute electrical stimulation of inferior thalamic peduncle and nucleus reticularis thalami in a patient with major depression disorder. Clin Neurophysiol 117:320-327, 2006

70. Ventura R, Cabib S, Puglisi-Allegra S: Genetic susceptibility of mesocortical dopamine to stress determines liability to inhibition of mesoaccumbens dopamine and to behavioral 'despair' in a mouse model of depression. Neuroscience 115:999-1007, 2002

71. Yang LM, Hu B, Xia YH, Zhang BL, Zhao H: Lateral habenula lesions improve the behavioral response in depressed rats via increasing the serotonin level in dorsal raphe nucleus. Behav Brain Res 188:84-90, 2008

72. Zangen A, Hyodo K: Transcranial magnetic stimulation induces increases in extracellular levels of dopamine and glutamate in the nucleus accumbens. Neuroreport 13:2401-2405, 2002

73. Zivin K, Kim HM, McCarthy JF, Austin KL, Hoggatt KJ, Walters $\mathrm{H}$, et al: Suicide mortality among individuals receiving treatment for depression in the Veterans Affairs health system: associations with patient and treatment setting characteristics. Am J Public Health 97:2193-2198, 2007

Manuscript submitted March 30, 2008.

Accepted April 24, 2008.

Address correspondence to: Jason S. Hauptman, M.D., Room 18-228 NPI, Box 957039, Los Angeles, California 90095-7039. email: jhauptman@mednet.ucla.edu. 